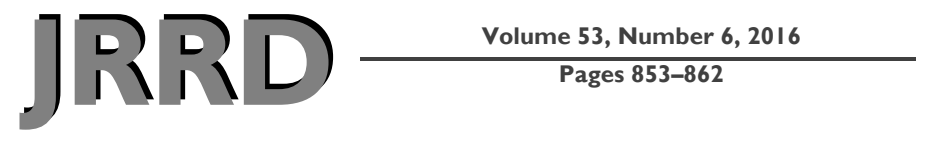

\title{
Implementation of a prediabetes identification algorithm for overweight and obese Veterans
}

\begin{abstract}
Tannaz Moin, MD, MBA, MSHS; ${ }^{1-2^{*}}$ Laura J. Damschroder, MS, MPH; ${ }^{3}$ Bradley Youles, MPA; ${ }^{3}$ Fatima Makki, MPH; ${ }^{3}$ Charles Billington, MD; ${ }^{4}$ William Yancy, MD, MHSc $;{ }^{5}$ Matthew L. Maciejewski, PhD; ${ }^{5}$ Linda S. Kinsinger, MD, MPH; ${ }^{6}$ Jane E. Weinreb, MD; $^{1}$ Nanette Steinle, MD; ${ }^{7}$ Caroline R. Richardson, MD $^{3,8}$

${ }^{1}$ Department of Veterans Affairs (VA) Greater Los Angeles Healthcare System, Los Angeles, CA; and David Geffen School of Medicine, University of California Los Angeles, Los Angeles, CA; ${ }^{2}$ Center for the Study of Healthcare Innovation, Implementation and Policy, Health Services Research \& Development, VA Greater Los Angeles Healthcare System, Los Angeles, CA; ${ }^{3}$ VA Center for Clinical Management Research, Ann Arbor, MI; ${ }^{4}$ Minneapolis VA Health Care System, Minneapolis, MN; and University of Minnesota Medical Center, Minneapolis, MN; ${ }^{5}$ Durham VA Medical Center (VAMC), Durham, NC; and Duke University School of Medicine, Durham, NC; ${ }^{6}$ National Center for Health Promotion and Disease Prevention, Veterans Health Administration, Durham, NC; ${ }^{7}$ Baltimore VAMC, Baltimore, MD; and University of Maryland School of Medicine, Baltimore, MD; ${ }^{8}$ Department of Family Medicine, University of Michigan, Ann Arbor, MI; and VA Diabetes Quality Enhancement Research Initiative, Ann Arbor, MI
\end{abstract}

\begin{abstract}
Type 2 diabetes prevention is an important national goal for the Veterans Health Administration (VHA): one in four Veterans has diabetes. We implemented a prediabetes identification algorithm to estimate prediabetes prevalence among overweight and obese Veterans at Department of Veterans Affairs (VA) medical centers (VAMCs) in preparation for the launch of a pragmatic study of Diabetes Prevention Program (DPP) delivery to Veterans with prediabetes. This project was embedded within the VA DPP Clinical Demonstration Project conducted from 2012 to 2015. Veterans who attended orientation sessions for an established VHA weight-loss program (MOVE!) were recruited from VAMCs with geographically and racially diverse populations using existing referral processes. Each site implemented and adapted the prediabetes identification algorithm to best fit its local clinical context. Sites relied on an existing referral process in which a prediabetes identification algorithm was implemented in parallel with existing clinical flow; this approach limited the number of overweight and obese Veterans who were assessed and screened. We evaluated 1,830 patients through chart reviews, interviews, and/or laboratory tests. In this cohort, our estimated prevalence rates for normal glycemic status, prediabetes, and diabetes were $29 \%(n=530), 28 \%(n=504)$, and $43 \%(n=796)$, respectively. Implementation of targeted prediabetes identification programs requires careful consideration of how prediabetes assessment and screening will occur.
\end{abstract}

Key words: diabetes, diabetes prevention, guidelines, health services research, implementation research, obesity, prediabetes, screening, Veterans, weight management.

Abbreviations: A1c $=$ hemoglobin A1c, ADA $=$ American Diabetes Association, $\mathrm{BMI}=$ body mass index, $\mathrm{CDC}=$ Centers for Disease Control and Prevention, DOD $=$ Department of Defense, DPP $=$ Diabetes Prevention Program, EMR $=$ electronic medical record, $\mathrm{FPG}=$ fasting plasma glucose, $\mathrm{IRB}=$ institutional review board, NCP $=$ National Center for Health Promotion and Disease Prevention, POC = point-of-care, QUERI = Quality Enhancement Research Initiative, SD = standard deviation, $\mathrm{VA}=$ Department of Veterans Affairs, VAMC = Department of Veterans Affairs medical center, VHA = Veterans Health Administration.

*Address all correspondence to Tannaz Moin, MD, MBA, MSHS; VA Greater Los Angeles Healthcare System, Mail Code 111D, 11301 Wilshire Blvd, Los Angeles, CA 90073; 310-478-3711, ext 48380; fax: 310-773-9206.

Email: Tannaz.moin@va.gov

http://dx.doi.org/10.1682/JRRD.2015.06.0104 


\section{INTRODUCTION}

Type 2 diabetes (referred to as diabetes throughout this article) is a common disease that is associated with significant morbidity and mortality. One in three U.S. adults 20 to $64 \mathrm{yr}$ and one in two adults $65 \mathrm{yr}$ or older have prediabetes [1], and studies have shown that 15 to 30 percent of patients with prediabetes can progress to diabetes in $5 \mathrm{yr}$ [2-3]. However, treating patients with intensive lifestyle interventions involving dietary change, physical activity, and weight loss can prevent one in seven cases of diabetes [46]. The 2002 Diabetes Prevention Program (DPP) study demonstrated that lifestyle interventions in patients with prediabetes significantly reduced the risk of progression to diabetes by up to 58 percent compared with placebo [4]. These landmark findings were confirmed by several other large randomized controlled trials [7] and have lasted up to $10 \mathrm{yr}$ in longitudinal observational studies [5,8-9]. As such, the Centers for Disease Control and Prevention (CDC) championed national initiatives to increase access to evidence-based lifestyle interventions for individuals at high risk for diabetes [10].

In an effort to decrease incident diabetes in Veterans, the Veterans Health Administration (VHA) National Center for Health Promotion and Disease Prevention (NCP) and the Diabetes Quality Enhancement Research Initiative (QUERI) partnered to conduct a DPP demonstration project for selected Veterans with prediabetes. A fundamental challenge in developing this Department of Veterans Affairs (VA) DPP Clinical Demonstration Project was identification of Veterans with prediabetes. Therefore, the objective of this embedded project was to implement a prediabetes identification algorithm for high-risk Veterans at three VA medical centers (VAMCs) and estimate the prevalence of prediabetes among overweight and obese Veterans. Understanding the prevalence of prediabetes among at-risk Veterans was critical for DPP capacity planning in the demonstration sites, and understanding barriers and facilitators to prediabetes assessment and screening would inform dissemination efforts if DPP-type programs were eventually to be implemented nationally.

\section{METHODS}

\section{Study Design and Population}

This was an implementation project embedded within the VA DPP Clinical Demonstration Project between 2012 and 2015 in partnership between VHA NCP and Diabetes QUERI. The institutional review board (IRB) at each VAMC site approved the research components related to the VA DPP Trial. Our team worked with clinical operations at three VAMCs to facilitate the implementation of prediabetes identification algorithms and processes at each site. Descriptive information about the implementation experiences of the local project teams is drawn upon for additional insights.

Veterans in the three VAMCs who attended an orientation session for an established VA weight-loss program, MOVE!, were eligible to participate. MOVE! is an evidence-based, multidisciplinary, comprehensive weightmanagement program that was nationally disseminated across all VAMCs in 2006 [11-14]. Veterans were referred to MOVE! by clinical providers or self-referred if they met MOVE! eligibility criteria (body mass index [BMI] $\geq 30 \mathrm{~kg} / \mathrm{m}^{2}$ or $\geq 25 \mathrm{~kg} / \mathrm{m}^{2}$ with one obesity-related condition, e.g., hypertension). Veterans who reported living more than $1 \mathrm{~h}$ travel distance were excluded because distance was a potential barrier to participation in a lifestyle intervention that included weekly face-to-face meetings.

\section{Prediabetes Identification Algorithm}

We used information from VHA electronic medical records (EMRs), interviews, and/or laboratory tests to classify patients as having normal glycemic status, prediabetes, or diabetes. Normal glycemic status was defined by hemoglobin A1c (A1c) $\leq 5.6$ percent or fasting plasma glucose (FPG) $\leq 99 \mathrm{mg} / \mathrm{dL}$ and no use of antiglycemic medications, including metformin, during the past 6 mo. Prediabetes was defined by (1) prior diagnosis of impaired fasting glucose or impaired glucose tolerance in the EMR problem list or (2) A1c 5.7 to 6.4 percent or FPG 100 to $125 \mathrm{mg} / \mathrm{dL}$ and no use of antiglycemic medications, including metformin, during the past 6 mo. Diabetes was defined by a prior diagnosis of diabetes in the EMR problem list, an A1c $\geq$ 6.5 percent or FPG $\geq 126 \mathrm{mg} / \mathrm{dL}$, or use of any antiglycemic medications during the past 6 mo [15].

To identify patients with a prior history of diabetes, study staff reviewed VHA EMRs, including pharmacy and laboratory data, and asked patients several interview questions. If a diabetes diagnosis was known or documented in the EMR, patients were classified as having diabetes. Among the remaining patients without a documented or known history of diabetes, prediabetes assessment and screening occurred in two sequential steps. The first step involved review of EMR data, including laboratory testing 
within prior 6 to $12 \mathrm{mo}$ and patient responses to several interview questions. Patients with a known or documented history of prediabetes were classified as having prediabetes. All remaining patients who had no known history of diabetes or prediabetes and no recent screening results available were invited to undergo laboratory screening. Patients referred to MOVE! have established risk factors for diabetes in which laboratory screening aligned with $\mathrm{CDC}$, American Diabetes Association (ADA), and VA/Department of
Defense (DOD) guidelines [10,15-16]. Thus, inviting MOVE! participants to have laboratory screening was considered quality improvement of routine care (and therefore did not require informed consent). CDC DPP thresholds for A1c and FPG were used to interpret laboratory results [10]. Patients were notified of their laboratory results using a standardized letter that was mailed to the patient and scanned into the VHA EMR. Figure 1 provides an overview of the

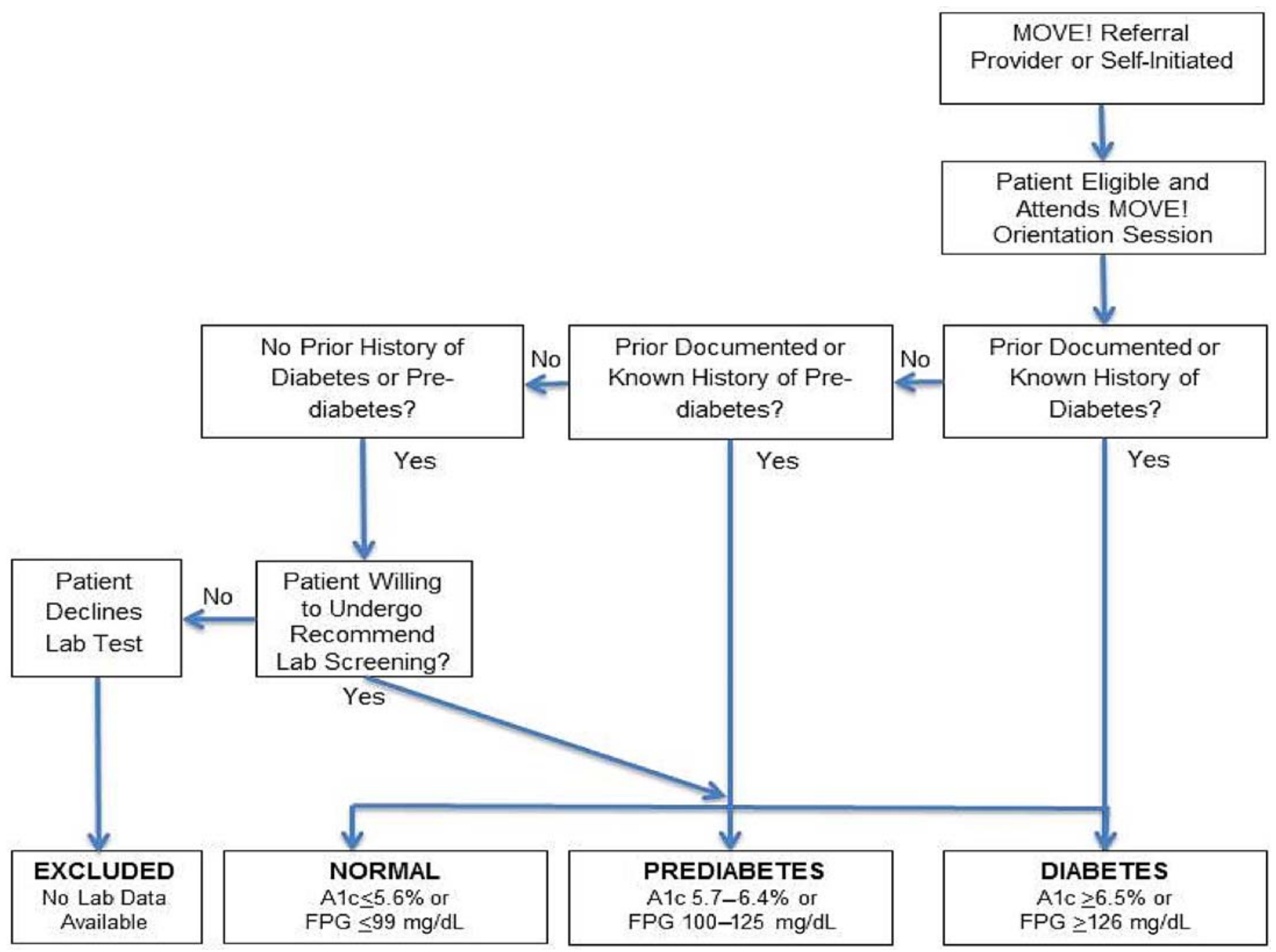

Figure 1.

Overview of prediabetes identification algorithm. Normal glycemic status was defined by hemoglobin A1c (A1c) $\leq 5.6$ percent or fasting plasma glucose (FPG) $\leq 99 \mathrm{mg} / \mathrm{dL}$ and no use of antiglycemic medications, including metformin, during the past 6 mo. Prediabetes was defined by (1) prior diagnosis of impaired fasting glucose or impaired glucose tolerance in the electronic medical record (EMR) problem list or (2) A1c 5.7 to 6.4 percent or FPG 100 to $125 \mathrm{mg} / \mathrm{dL}$ and no use of antiglycemic medications, including metformin, during the past 6 mo. Diabetes was defined by a prior diagnosis of diabetes in the EMR problems list, an A1c $\geq 6.5$ percent, an $F P G \geq 126 \mathrm{mg} / \mathrm{dL}$, or use of any antiglycemic medications during the past 6 mo. 
prediabetes identification algorithm each site adapted and integrated into existing clinical operations.

\section{Data Collection and Statistical Analysis}

From the results of the evaluation process, we estimated the prevalence of normal glycemic status, prediabetes, and diabetes. To examine demographic and other differences between patients in these three glycemic status groups, we obtained VHA data on age, sex, weight, BMI, A1c, comorbidities, and service-connected disability benefits from the VHA Corporate Data Warehouse, a national data repository comprising data from several VHA clinical and administrative systems. Descriptive analyses were used to estimate prevalence of prediabetes in this cohort and to report demographic characteristics. Analysis of variance and chi-square analyses were conducted using SAS version 9.3 (SAS Institute Inc; Cary, North Carolina) to compare characteristics among glycemic status groups. Analyses were conducted from 2013 to 2015.

\section{RESULTS}

\section{Prevalence of Prediabetes and Patient Characteristics by Glycemic Status}

Between July 2012 and January 2015 we evaluated 1,830 patients at three VAMCs through a process of chart reviews, interviews, and/or laboratory tests (Table 1). In this cohort, the estimated prevalence rates for normal glycemic status, prediabetes, and diabetes were 29 percent $(n=530)$, 28 percent $(n=504)$, and 43 percent $(n=796)$, respectively.
On average, participants with prediabetes were $58 \mathrm{yr}$ (standard deviation [SD] $=9.9 \mathrm{yr}$ ) with a BMI of $34.8 \mathrm{~kg} /$ $\mathrm{m}^{2}\left(\mathrm{SD}=5.7 \mathrm{~kg} / \mathrm{m}^{2}\right)$ and $\mathrm{A} 1 \mathrm{c}$ of 6.0 percent $(\mathrm{SD}=$ $0.2 \%)$. On average, participants with normal glycemic status were younger (53 yr) with similar BMIs $(34.8 \mathrm{~kg} /$ $\left.\mathrm{m}^{2}\right)$, while participants with diabetes were older $(61.5 \mathrm{yr})$ and had higher BMIs $\left(37.1 \mathrm{~kg} / \mathrm{m}^{2}\right)$. Medical comorbidities such as hypertension, dyslipidemia, coronary artery disease, and congestive heart failure occurred most frequently among patients with diabetes and least frequently among patients with normal glycemic status (Table 2).

\section{Adaptations of Screening Implementation}

Prior to the VA DPP Clinical Demonstration Project, none of the three study sites were systematically assessing and/or screening MOVE!-referred patients for prediabetes. Sites made local decisions about the manner in which the prediabetes identification algorithm was implemented in order to integrate with existing local clinical operations and workflow. The specifics of how the identification algorithm was implemented varied between sites; however, all sites used the same eligibility criteria to classify patients as having normal glycemic status, prediabetes, or diabetes.

Site 1 was located on the West Coast and had the highest number of MOVE! attendees among the three sites (Table 1). Site 1 MOVE! referrals largely came from primary care providers who used a preexisting EMR template to refer patients to MOVE!. The study team partnered with clinical informatics at this site to revise the existing electronic MOVE! referral template to facilitate the evaluation process. After discussing proposed changes with

Table 1.

Site-specific characteristics and results.

\begin{tabular}{|c|c|c|c|c|}
\hline Characteristic & Site 1 & Site 2 & Site 3 & p-Value* \\
\hline Geographic Location & West Coast & Midwest & East Coast & - \\
\hline Unique Outpatient Visits Annually, $n$ & 87,210 & 98,431 & 56,424 & - \\
\hline VA DPP Prediabetes Assessment Rate,$^{\dagger} n$ & 19 & 17 & 18 & - \\
\hline Patients Assessed and Screened, $n$ & 763 & 571 & 496 & - \\
\hline Patients with Prediabetes, $n(\%)^{\ddagger}$ & $237(31)$ & $125(22)$ & $142(29)$ & 0.003 \\
\hline Patients with Normal Glycemic Status, $n(\%)$ & $222(29)$ & $171(30)$ & $137(28)$ & 0.003 \\
\hline \multicolumn{5}{|c|}{$\begin{array}{l}{ }^{*} p \text {-values demonstrate whether the three groups are different or not. } \\
\text { †Per } 1,000 \text { patients assigned to a primary care panel. } \\
\text { FIncludes patients with a known or documented diagnosis (based on chart review and interviews) and those who were newly diagnosed with laboratory screening } \\
\text { Percentages are rounded to the nearest percent and may not add to } 100 \text { due to rounding. } \\
\text { DPP = Diabetes Prevention Program, VA = Department of Veterans Affairs. }\end{array}$} \\
\hline
\end{tabular}


Table 2.

Participant characteristics.

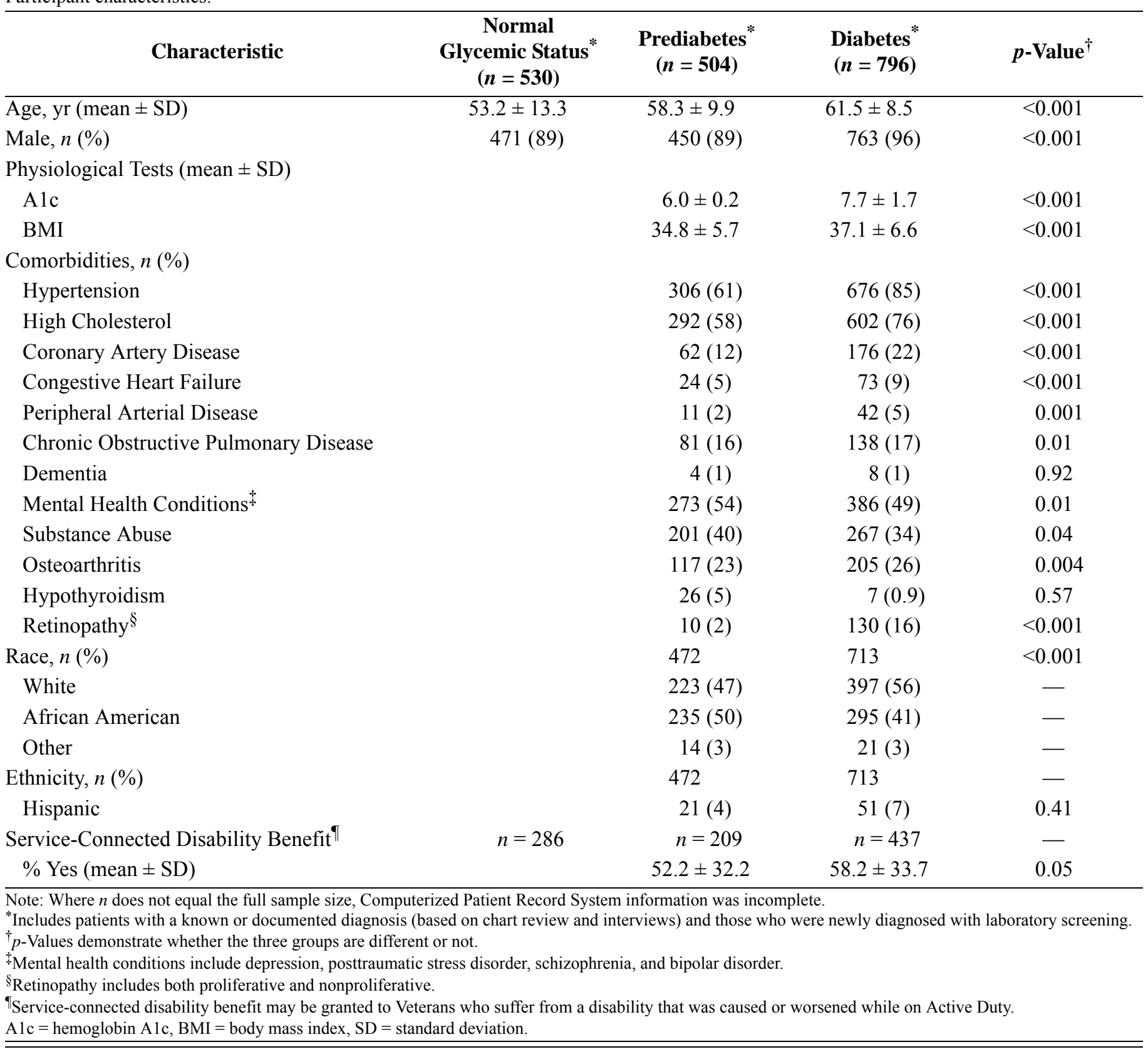

stakeholders in primary care and MOVE!, the study team met regularly with clinical informatics over several weeks to design and implement proposed changes. After changes were implemented, the electronic MOVE! referral template automatically searched for and inserted patients' most recent A1c test (if it was available within the prior $6 \mathrm{mo}$ ). If no result was found, the system prompted an order for an A1c screening test after the provider com- pleted the MOVE! consult request. The decision to order the Alc screening had no effect on the referral overall (i.e., if the provider did not want to order a test they could simply close the laboratory order).

Site 2 was located in the Midwest and had an intermediate number of MOVE! attendees among the three sites (Table 1). Site 2 MOVE! referrals came from primary care providers or were patient initiated. Similar to Site 1, 
providers at Site 2 also used a preexisting template within the EMR to refer patients to MOVE!. More often, however, patients self-referred to MOVE! by requesting an appointment from clinic staff, who entered referrals into the system. This site conducted additional outreach to help recruit patients with BMI $\geq 35 \mathrm{~kg} / \mathrm{m}^{2}$. Site 3 , which was located on the East Coast and had the lowest number of MOVE! attendees (Table 1), did not use an electronic MOVE! referral process. Instead, information about MOVE! was provided to candidate patients from a variety of sources (e.g., providers, support staff, and informational flyers or bulletins). Patients requested MOVE! appointments by contacting a scheduler in person or by phone in any of the outpatient clinics.

At all three sites, patients who attended a MOVE! orientation session were invited to have laboratory screening if they had no known diagnosis of prediabetes or diabetes and had not already completed laboratory testing within the last 6 mo. All sites also chose to rely on A1c testing instead of FPG testing. Site 3 used point-of-care (POC) A $1 \mathrm{c}$ testing, but Sites 1 and 2 used laboratory A1c testing.

\section{DISCUSSION}

To our knowledge, this study is the first to examine the prevalence of prediabetes in a cohort of overweight and obese Veterans and to describe implementation experiences and recommendations for prediabetes assessment and screening in three VAMCs. Each site made unique adaptations to the prediabetes identification algorithm to fit its own local clinical context. These adaptations helped us identify five critical decision points for implementation of prediabetes assessment and screening programs (Figure 2).

The first important decision point focuses on who will be targeted for prediabetes assessment and screening. We focused on evaluating high-risk individuals with known risk factors for diabetes. National guidelines specify that diabetes screening can be considered in individuals with $\mathrm{BMI} \geq 25 \mathrm{~kg} / \mathrm{m}^{2}$ or any other recognized risk factor for developing diabetes, including cardiovascular disease, hypertension, dyslipidemia, polycystic ovarian syndrome, physical inactivity, having a first-degree relative with diabetes, and having a high-risk race/ethnicity $[10,15-16]$. Even in the absence of these criteria, testing for diabetes can be considered beginning at $45 \mathrm{yr}$ of age [10,15-16]. Although the ADA and VA/DOD make discrete recommendations regarding whom to screen, our
1. WHO are you assessing and screening?

- Risk of screening pool

\section{WHEN are you assessing and screening?}

- Context of clinical flow

\section{WHAT are you doing for outreach?}

- Patient education and awareness

\section{WHERE is your link to primary care?}

- Coordination with primary care

- Patient management and follow-up

\section{HOW is laboratory screening conducted?}

- A1c, FPG, OGTT

- POC vs. laboratory testing

\section{Figure 2.}

Five decision points for a prediabetes assessment and screening program. $\mathrm{A} 1 \mathrm{c}=$ hemoglobin $\mathrm{A} 1 \mathrm{c}, \mathrm{FPG}=$ fasting plasma glucose, $\mathrm{OGTT}=$ oral glucose tolerance test, $\mathrm{POC}=$ point-of-care .

cohort of patients with significant risk factors for diabetes, including obesity, were not being systematically assessed at the three sites prior to this project. Thus, the question of whom to assess and screen in real-world clinical settings was not straightforward in these three VAMCs and may also vary by clinical setting and population in other patient groups.

Overall, population-wide diabetes screening remains controversial [17-19]. The benefit of early prediabetes detection is the opportunity to prevent diabetes because those who screen positive can be referred to intensive lifestyle interventions. When resources are not available to sustain DPP translations, limiting assessment and screening to populations at high risk for diabetes may help minimize the number of individuals to evaluate and more precisely target interventions to individuals with prediabetes who would benefit most from a DPP-based lifestyle intervention or in whom diabetes screening may actually be cost-saving [20-21]. However, assessment and screening may not be necessary in health systems in which 
lifestyle interventions are widely accessible. Thus, who will be assessed and screened should be informed by both the local population and available resources.

The second and overlapping decision point is when assessment and screening will take place. We chose to rely on an existing MOVE! referral process because it enabled sites to implement a prediabetes identification algorithm in a relatively short time frame, requiring few additional resources. However, this approach also limited the scope of our evaluation to overweight and obese individuals attending MOVE! orientation sessions. It is likely that only a small portion of all high-risk patients were ultimately evaluated because of the relatively low proportion of candidates who attend at least one MOVE! session [22]. The prevalence rate $(28 \%)$ of prediabetes in this cohort of 1,830 overweight and obese Veterans across three VAMCs was surprisingly low compared with CDC estimates for the general population (37\%) [23]. This low prevalence may be partially explained by the high prevalence rate $(43 \%)$ of diabetes in this cohort, suggesting that the window of opportunity to prevent diabetes was missed by the time many attended a MOVE! orientation session. Thus, even in a system that already has very high rates of screening for obesity (95\%) and a robust weightmanagement program (MOVE!), targeted identification of prediabetes was challenging [22]. Therefore, integration within the context of local clinical processes is critical, but real-time adaptations may be needed to optimize uptake and reach among individuals at highest risk.

The third decision point is what outreach is needed. Awareness of the importance of assessment and screening can affect a provider's willingness to refer a patient for screening and a patient's willingness to undergo screening. Additionally, studies have shown that patients are often not aware of prediabetes as a medical issue [21,24-25]. Even when both provider and patient are aware, prediabetes may not be prioritized when managing long problem lists during short office visits. Thus, it is important to consider outreach at all levels (patient, provider, and organization). Increasing awareness of prediabetes as an important and modifiable health issue may help improve the variable patient engagement demonstrated in translational DPP studies [26-27]. For example, public health messages focused on diabetes prevention may help improve patient awareness of prediabetes and diabetes prevention.

The fourth decision point is where the link to primary care will take place. Primary care providers are best positioned to influence whether an individual should be assessed or screened for diabetes because of their direct contact and relationships with patients. Assessment and screening results should be communicated or made readily available to primary care providers who are responsible for patients' long-term care. Primary care providers may need to triage patients to other needed services or consider further treatment for individuals who need follow-up. Therefore, it is important that providers have access to results and are updated on their patients' status to optimize long-term care. In our project, all patients who underwent laboratory screening received a standardized letter explaining their results. Both the laboratory results and a copy of the mailed letter were easily accessible to all providers through the VHA EMR. In these ways, we tried to address the need for increased awareness and communication with both the patient and provider. The robust EMR and vertical integration of the VHA facilitated these efforts, but achieving these simple steps may be more difficult in other settings.

The fifth decision point is how assessment and screening are conducted. Laboratory screening can rely on an FPG, A1c, or oral glucose tolerance test. All three sites preferred A1c over FPG testing because of its exemption from fasting, potentially greater preanalytical stability, and fewer day-to-day perturbations during stress or illness [15]. Studies have also demonstrated a strong, continuous association between A1c and subsequent diabetes comparable to FPG testing [15]. Evidence also suggests that baseline A1c may be a stronger predictor of subsequent diabetes and cardiovascular events in African Americans and non-Hispanic white adults without diabetes [15,28].

Site 3 incorporated POC A1c testing because it was already routinely used in outpatient clinics and was therefore relatively easy to incorporate into MOVE! orientation sessions. In contrast, Site 1 tried to initiate POC testing but experienced significant delays because POC A1c was not already integrated into existing clinical operations. Site 2 considered POC A1c testing, but it was not organizationally supported. It is worth noting that ADA guidelines recommend all A1c testing be done by a procedure certified by the National Glycohemoglobin Standardization Program and standardized to the Diabetes Control and Complications Trial assay [15,29]. Although studies have shown that the commercially available POC instruments such as DCA Vantage (Siemens Healthineers; Malvern, Pennsylvania; used in Site 3), Afinion (Alere; Waltham, Massachusetts), cobas b 101 (Roche Diagnostics; Risch-Rotkreuz, Switzerland), and B-analyst (A. Menarini Diagnostics; Firenze, 
Italy) meet generally accepted performance criteria for A1c [30], ADA guidelines do not yet endorse the use of POC A1c for diagnosis [15]. Overall, the relative advantages and disadvantages of each screening method should be considered and balanced with the needs of the population being targeting.

Our project has several limitations. First, confirmatory or repeat laboratory testing, although recommended to all participants and primary care providers, was not part of the assessment and screening algorithm. However, in almost all cases a single A1c screening test was the test of choice, which has been shown to be highly specific with much lower intraindividual biological variation and fewer false-positive diagnoses than FPG testing [31]. Second, our study cohort included predominantly male Veterans from three VAMCs. Participants were quite diverse on many characteristics, including geographic location and race/ethnicity, but the low participation of females and non-Veterans may limit generalizability. Last, only the subset of patients who attended a MOVE! orientation session were evaluated. It is likely that less motivated patients were missed because they did not attend MOVE! orientation after referral or a referral was never placed.

\section{CONCLUSIONS}

Our study describes implementation experiences of a prediabetes identification algorithm targeted to overweight and obese individuals who attended a weightmanagement orientation session where the estimated prevalence of diabetes (43\%) was nearly double the prevalence of prediabetes $(28 \%)$. Study sites relied on an existing MOVE! referral process, which made implementation of a prediabetes identification algorithm relatively efficient, but this approach may have overly restricted assessment and screening by limiting the number of overweight and obese Veterans who had the opportunity to be evaluated. Our experience highlights the importance of carefully considering who receives prediabetes assessment and screening, when and where it takes place, what is being done to raise awareness of its importance, and how it is conducted. National guidelines recommend prediabetes screening based on diabetes risk factors and age, but this approach needs to be balanced with local patient characteristics, clinical flow, and available resources.

\section{ACKNOWLEDGMENTS}

\section{Author Contributions:}

Study concept and design: T. Moin, L. J. Damschroder, L. S. Kinsinger, C. R. Richardson.

Acquisition of data: L. J. Damschroder, B. Youles, F. Makki, C. R. Richardson.

Analysis and interpretation of data: T. Moin, L. J. Damschroder, F. Makki, C. R. Richardson.

Drafting of manuscript: T. Moin, L. J. Damschroder, B. Youles, C. R. Richardson.

Critical revision of manuscript for important intellectual content:

T. Moin, L. J. Damschroder, B. Youles, F. Makki, C. Billington,

W. Yancy, M. L. Maciejewski, L. S. Kinsinger, J. E. Weinreb, N. Steinle, C. R. Richardson.

Statistical analysis: T. Moin, L. J. Damschroder, F. Makki, C. R. Richardson.

Study supervision: L. J. Damschroder, C. R. Richardson.

Financial Disclosures: The authors have declared that no competing interests exist.

Funding/Support: This material was based on work supported by the VA (awards XVA 41-048, RRP 12-440, and SDP 12-549). Dr. Moin received support from the VA Office of Academic Affiliations through the VA Health Services Research and Development Advanced Fellowship Program (award TPM65-010), VA Greater Los Angeles, from 2011 to 2014.

Additional Contributions: The authors would like to thank Ms. Maria Hughes for project management support, Ms. Jenny Davis for help with the statistical analysis, and Dr. Caroline Goldzweig and her clinical informatics team for their assistance in revising the electronic referrals. The authors would also like to recognize the support provided by the VA DPP health coaches and MOVE! coordinators at all three VAMC sites.

Institutional Review: This was an implementation project embedded within the VA DPP Clinical Demonstration Project in partnership between VHA NCP and Diabetes QUERI. The IRB at each VAMC site approved the research components related to the VA DPP Trial. Inviting MOVE! participants to have laboratory screening was considered quality improvement of routine care; therefore, neither VA review board approval nor informed consent was required.

Participant Follow-Up: The authors do not plan to inform participants of the publication of this study.

\section{REFERENCES}

1. Centers for Disease Control and Prevention. National diabetes statistics report: Estimates of diabetes and its burden in the United States, 2014. Atlanta (GA): U.S. Department of Health and Human Services; 2014. 12 p. Available from: http://www.cdc.gov/diabetes/pubs/statsreport14/nationaldiabetes-report-web.pdf

2. Nichols GA, Hillier TA, Brown JB. Progression from newly acquired impaired fasting glucose to type 2 diabetes. 
Diabetes Care. 2007;30(2):228-33. [PMID:17259486]

http://dx.doi.org/10.2337/dc06-1392

3. Centers for Disease Control and Prevention. Prediabetes: Could it be you? [Internet]. Atlanta (GA): U.S. Department of Health and Human Services; 2014 [cited 2016 Oct 4]. Available from: http://www.cdc.gov/diabetes/pubs/statsreport14/ prediabetes-infographic.pdf.

4. Knowler WC, Barrett-Connor E, Fowler SE, Hamman RF, Lachin JM, Walker EA, Nathan DM; Diabetes Prevention Program Research Group. Reduction in the incidence of type 2 diabetes with lifestyle intervention or metformin. N Engl J Med. 2002;346(6):393-403. [PMID:11832527] http://dx.doi.org/10.1056/NEJMoa012512

5. Diabetes Prevention Program Research Group; Knowler WC, Fowler SE, Hamman RF, Christophi CA, Hoffman HJ, Brenneman AT, Brown-Friday JO, Goldberg R, Venditti E, Nathan DM. 10-year follow-up of diabetes incidence and weight loss in the Diabetes Prevention Program Outcomes Study. Lancet. 2009;374(9702):1677-86. [PMID:19878986] http://dx.doi.org/10.1016/S0140-6736(09)61457-4

6. Orchard TJ, Temprosa M, Barrett-Connor E, Fowler SE, Goldberg RB, Mather KJ, Marcovina SM, Montez M, Ratner RE, Saudek CD, Sherif H, Watson KE; Diabetes Prevention Program Outcomes Study Research Group. Long-term effects of the Diabetes Prevention Program interventions on cardiovascular risk factors: A report from the DPP Outcomes Study. Diabet Med. 2013;30(1):46-55. [PMID:22812594] http://dx.doi.org/10.1111/j.1464-5491.2012.03750.x

7. Lindström J, Louheranta A, Mannelin M, Rastas M, Salminen V, Eriksson J, Uusitupa M, Tuomilehto J; Finnish Diabetes Prevention Study Group. The Finnish Diabetes Prevention Study (DPS): Lifestyle intervention and 3-year results on diet and physical activity. Diabetes Care. 2003; 26(12):3230-36. [PMID:14633807] http://dx.doi.org/10.2337/diacare.26.12.3230

8. Li G, Zhang P, Wang J, Gregg EW, Yang W, Gong Q, Li H, Li H, Jiang Y, An Y, Shuai Y, Zhang B, Zhang J, Thompson TJ, Gerzoff RB, Roglic G, Hu Y, Bennett PH. The longterm effect of lifestyle interventions to prevent diabetes in the China Da Qing Diabetes Prevention Study: A 20-year follow-up study. Lancet. 2008;371(9626):1783-89. [PMID:18502303] http://dx.doi.org/10.1016/S0140-6736(08)60766-7

9. Lindström J, Ilanne-Parikka P, Peltonen M, Aunola S, Eriksson JG, Hemiö K, Hämäläinen $\mathrm{H}$, Härkönen $\mathrm{P}$, Keinänen-Kiukaanniemi S, Laakso M, Louheranta A, Mannelin M, Paturi M, Sundvall J, Valle TT, Uusitupa M, Tuomilehto J; Finnish Diabetes Prevention Study Group. Sustained reduction in the incidence of type 2 diabetes by lifestyle intervention: Follow-up of the Finnish Diabetes Prevention Study. Lancet. 2006;368(9548):1673-79.

\section{[PMID: 17098085]}

http://dx.doi.org/10.1016/S0140-6736(06)69701-8

10. Centers for Disease Control and Prevention. Diabetes Prevention and Recognition Program [Internet]. Atlanta (GA): U.S. Department of Health and Human Services; 2011 [updated 2016 Jan 14; cited 2015 Jun 4]. Available from: http://www.cdc.gov/diabetes/prevention/recognition

11. Kinsinger LS, Jones KR, Kahwati L, Harvey R, Burdick M, Zele V, Yevich SJ. Design and dissemination of the MOVE! Weight-Management Program for Veterans. Prev Chronic Dis. 2009;6(3):A98. [PMID:19527600]

12. McVay MA, Yancy WS Jr, Vijan S, Van Scoyoc L, Neelon B, Voils CI, Maciejewski ML. Obesity-related health status changes and weight-loss treatment utilization. Am J Prev Med. 2014;46(5):465-72. [PMID:24745636] http://dx.doi.org/10.1016/j.amepre.2013.11.018

13. Romanova M, Liang LJ, Deng ML, Li Z, Heber D. Effectiveness of the MOVE! Multidisciplinary weight loss program for veterans in Los Angeles. Prev Chronic Dis. 2013;10:120325. [PMID:23823701]

http://dx.doi.org/10.5888/pcd10.120325

14. Dahn JR, Fitzpatrick SL, Llabre MM, Apterbach GS, Helms RL, Cugnetto ML, Klaus J, Florez H, Lawler T. Weight management for veterans: Examining change in weight before and after MOVE! Obesity (Silver Spring). 2011;19(5):977-81. [PMID:21127474] http://dx.doi.org/10.1038/oby.2010.273

15. American Diabetes Association. Standards of medical care in diabetes - 2014. Diabetes Care. 2014;37(Suppl 1):S14-80. [PMID:24357209]

16. Department of Veterans Affairs/Department of Defense. VA/DoD clinical practice guideline for the management of diabetes mellitus. Washington (DC): U.S. Department of Veterans Affairs; 2010 [cited 2015 Jun 4]. Available from: http://www.healthquality.va.gov/guidelines/CD/diabetes/ DM2010 FUL-v4e.pdf

17. Casagrande SS, Cowie CC, Fradkin JE. Utility of the U.S. Preventive Services Task Force criteria for diabetes screening. Am J Prev Med. 2013;45(2):167-74. [PMID:23867023] http://dx.doi.org/10.1016/j.amepre.2013.02.026

18. Waugh N, Scotland G, McNamee P, Gillett M, Brennan A, Goyder E, Williams R, John A. Screening for type 2 diabetes: Literature review and economic modelling. Health Technol Assess. 2007;11(17):iii-iv, ix-xi, 1-125.

[PMID: 17462167]

19. Waugh NR, Shyangdan D, Taylor-Phillips S, Suri G, Hall B. Screening for type 2 diabetes: A short report for the National Screening Committee. Health Technol Assess. 2013;17(35):1-90. [PMID:23972041]

http://dx.doi.org/10.3310/hta17350

20. Chatterjee R, Narayan KM, Lipscomb J, Jackson SL, Long Q, Zhu M, Phillips LS. Screening for diabetes and predia- 
betes should be cost-saving in patients at high risk. Diabetes Care. 2013;36(7):1981-87. [PMID:23393215]

http://dx.doi.org/10.2337/dc12-1752

21. Centers for Disease Control and Prevention (CDC). Awareness of prediabetes-United States, 2005-2010. MMWR Morb Mortal Wkly Rep. 2013;62(11):209-12. [PMID:23515058]

22. Kahwati LC, Lance TX, Jones KR, Kinsinger LS. RE-AIM evaluation of the Veterans Health Administration's MOVE! Weight Management Program. Transl Behav Med. 2011; 1(4):551-60. [PMID:24073079] http://dx.doi.org/10.1007/s13142-011-0077-4

23. Centers for Disease Control and Prevention. National diabetes fact sheet: National estimates and general information on diabetes and prediabetes in the United States. Atlanta (GA): U.S. Department of Health and Human Services, Centers for Disease Control and Prevention; 2011. http://www.familydocs.org/f/CDC $\% 20$ Diabetes $\% 20$ fact $\% 20$ sheet-2011.pdf

24. Geiss LS, James C, Gregg EW, Albright A, Williamson DF, Cowie CC. Diabetes risk reduction behaviors among U.S. adults with prediabetes. Am J Prev Med. 2010;38(4):403-9. [PMID:20307809] http://dx.doi.org/10.1016/j.amepre.2009.12.029

25. Zimmermann LJ, Thompson JA, Persell SD. Electronic health record identification of prediabetes and an assessment of unmet counselling needs. J Eval Clin Pract. 2012; 18(4):861-65. [PMID:21689215] http://dx.doi.org/10.1111/j.1365-2753.2011.01703.x

26. Laws RA, St George AB, Rychetnik L, Bauman AE. Diabetes prevention research: A systematic review of external validity in lifestyle interventions. Am J Prev Med. 2012; 43(2):205-14. [PMID:22813687] http://dx.doi.org/10.1016/j.amepre.2012.04.017

27. Matthews L, Kirk A, Macmillan F, Mutrie N. Can physical activity interventions for adults with type 2 diabetes be translated into practice settings? A systematic review using the RE-AIM framework. Transl Behav Med. 2014;4(1):60-78. [PMID:24653777] http://dx.doi.org/10.1007/s13142-013-0235-y
28. Selvin E, Steffes MW, Zhu H, Matsushita K, Wagenknecht L, Pankow J, Coresh J, Brancati FL. Glycated hemoglobin, diabetes, and cardiovascular risk in nondiabetic adults. N Engl J Med. 2010;362(9):800-11. [PMID:20200384] http://dx.doi.org/10.1056/NEJMoa0908359

29. Gillett MJ. International Expert Committee report on the role of the A1c assay in the diagnosis of diabetes: Diabetes Care 2009;32(7):1327-1334. Clin Biochem Rev. 2009; 30(4):197-200. [PMID:20011212]

30. Lenters-Westra E, Slingerland RJ. Three of 7 hemoglobin Alc point-of-care instruments do not meet generally accepted analytical performance criteria. Clin Chem. 2014; 60(8):1062-72. [PMID:24865164] http://dx.doi.org/10.1373/clinchem.2014.224311

31. Bennett CM, Guo M, Dharmage SC. HbA(1c) as a screening tool for detection of Type 2 diabetes: A systematic review. Diabet Med. 2007;24(4):333-43. [PMID:17367307] http://dx.doi.org/10.1111/j.1464-5491.2007.02106.x

Submitted for publication June 4, 2015. Accepted in revised form March 30, 2016.

This article and any supplementary material should be cited as follows:

Moin T, Damschroder LJ, Youles B, Makki F, Billington C, Yancy W, Maciejewski ML, Kinsinger LS, Weinreb JE, Steinle N, Richardson CR. Implementation of a prediabetes identification algorithm for overweight and obese Veterans. J Rehabil Res Dev. 2016;53(6):853-62.

http://dx.doi.org/10.1682/JRRD.2015.06.0104

ORCID: Tannaz Moin, MD, MBA, MSHS: 0000-00025035-6641

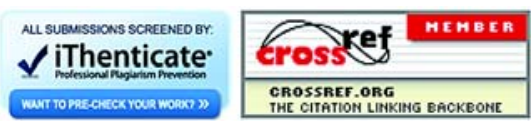

